\title{
A REVIEW OF SURGICAL RESULTS IN HIATUS HERNIA
}

\author{
BY \\ J. LEIGH COLLIS \\ From the Queen Elizabeth Hospital, Birmingham
}

(RECEIVED FOR PUBLICATION DECEMBER 19, 1960)

In 1954 a paper was published (Collis, Kelly, and Wiley) which described a study of the control of reflux at the lower end of the oesophagus and put forward an operative technique based on the findings. This operation has been used since that time, and this paper gives the experience from the first 200 consecutive cases. The period covered is from March, 1953, to March, 1960, but of special interest are the findings from the cases done before March, 1956, because from them a four-year follow-up is available.

\section{PRINCIPLES}

In order to restate the case for the particular operative plan used, certain rather elementary aspects of the mechanism for the control of reflux must be mentioned. The methods by which this control is brought about may be listed under four headings. First there is the obliquity of the insertion of the oesophagus into the stomach; secondly the sling fibres in the stomach (Barrett, 1952) ; thirdly the muscle fibres of the right crus ; and lastly the weak sphincter of the lower end of the oesophagus. This position may be further simplified by saying that the forces act either as a direct sphincter or by maintaining or increasing the angle of implantation of the oesophagus into the stomach.

When a sliding type hiatus hernia is present the relations of the stomach and oesophagus take the shape of an inverted thistle funnel with the angle of implantation completely removed. In this circumstance only the sphincter mechanisms remain to control reflux, and, as is well known, they are usually too weak to be effective. In the normal arrangement or when the hernia is paraoesophageal the angle of implantation is acute and the control of reflux is good. The relation between the oesophagus and the stomach under these circumstances takes a shape generally reminiscent of a retort.

The first object of this operation is to convert the pattern from that of the thistle funnel to that of the retort. In the case of the para-oesophageal hernia the retort pattern already exists, and so the object here is to reduce the hernia while maintaining the same relationship with the cardia below the diaphragm. The second and much less important object is to reduce the size of the oesophageal hiatus so as to reintroduce the scissor action of the right crus.

The oesophagus passes between the two halves of the right crus in the posterior part of the diaphragm. In this area the diaphragm is coming steeply upwards and then curving forwards to a more horizontal direction. As a result the diaphragm is passing upwards and a little forwards at the point that the oesophagus passes through it. The wider the hiatus is, the higher is the oesophagus in its passage through the diaphragm and consequently the more obtuse is the angle of implantation into the stomach. Conversely, the smaller the hiatus is, the lower it is and the more acute is the angle of implantation. In the area adjacent to the tendon of the right crus the direction of the diaphragm is vertically upwards. The closer

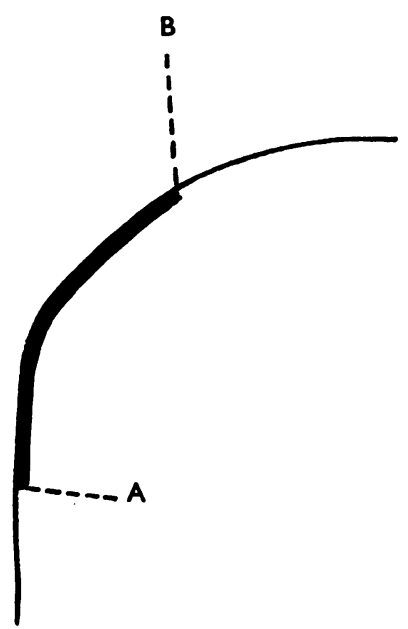

FIG. 1.-This represents the area of the hiatus. At $B$ the curve is flattening and approaching the horizontal. At $\mathbf{A}$ the direction is almost vertical. 


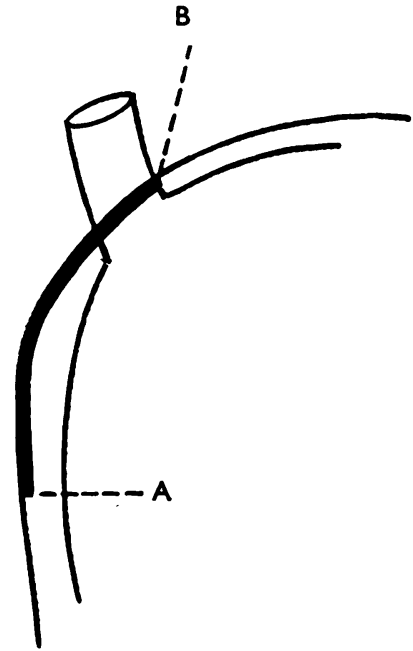

Fig. 2.-In this diagram the oesophagus is passing through the top of the hiatal opening and the angle of implantation is obtuse.

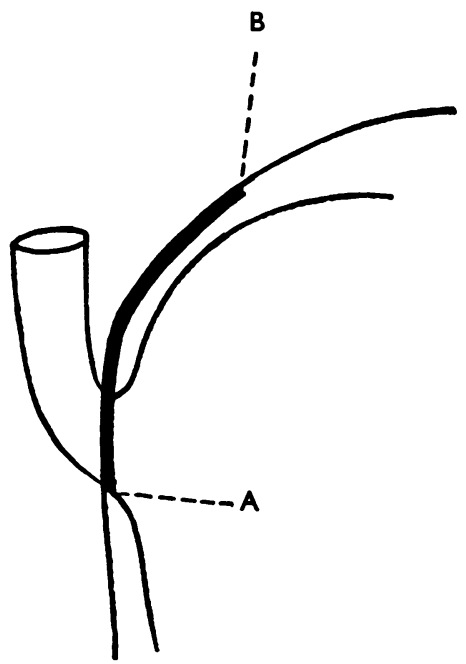

Fig. 3.-Here th oesophagus is passing through the lower part of the hiatal opening and the angle of implantation is acute. This is the desired position and therefore the stitches must be put in above the oesophagus. The amount of improvement from $B$ downwards which is produced with each stitch is greater with each stitch inserted. This is because the general direction of the curve of the diaphragm is becoming more vertical.

the cardia is to the top of the tendon of the right crus the more acute will be the angle of implantation. In stitching the two halves of the right crus together, to keep the cardia in this position, a greater degree of benefit will be effected from stitches placed where the diaphragm is most vertical. It will therefore be seen that as the diaphragm becomes more vertical each stitch has a magnified effect. For this reason a very careful dissection of the right crus is necessary in the area of the tendon. It has been found that this can be best exposed through an abdomino-thoracic incision, but there is no doubt that the operation could be done by other routes as from a purely thoracic or abdominal approach as advocated by Tanner (1955)

Having performed the dissection of the right crus the arrangement of the double-breasted overlap will be found (Collis et al., 1954). When this is opened up the oesophagus can be laid obliquely through the substance of the diaphragm along the

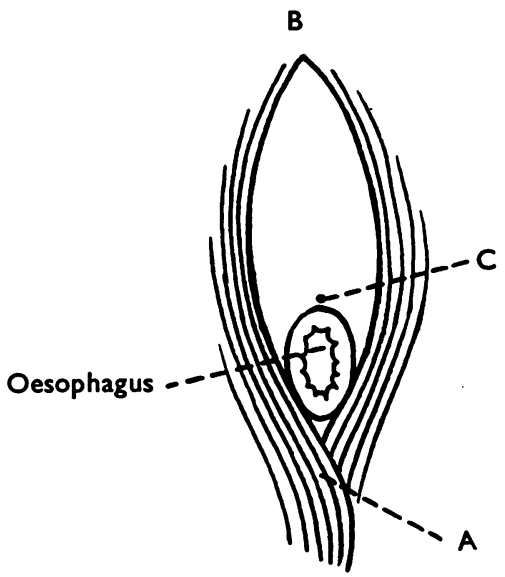

FIG. 4.-This represents the oesophagus passing through the right crus. The oesophagus has been placed in position for suturing between $B$ and $C$. A is at the position of the double-breasted overlap at the top of the tendon of the right crus.

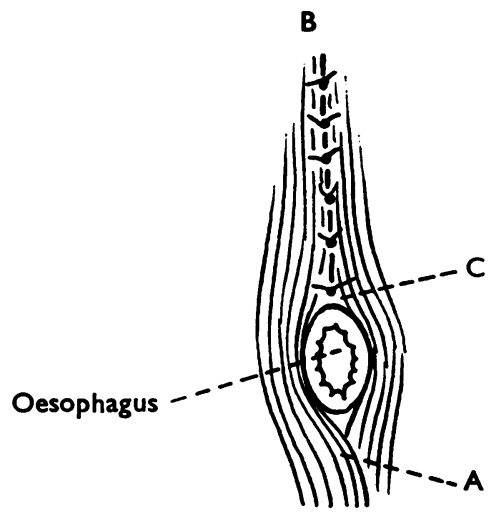

FIG. 5.-The sutures between $B$ and $C$ have now been inserted and the oesophagus now lies adjacent to the top of the tendon and the right crus. 
top of the tendon of the right crus. The reduction in the size of the opening between the two halves must now be made from above downwards so as to retain the point around which the oesophagus angulates as low as possible. This makes for the sharpest acuity of the angle of the implantation of the oesophagus into the stomach. In the standard Allison (1948) operation the limbs of the right crus are sutured together below and behind the oesophagus. The result is to displace the oesophagus to the highest part of the hiatus and so make the angle of implantation more obtuse. This might be put another way by saying that the general shape remains similar to an inverted thistle funnel and quite unlike a retort. Again it makes the position less like the acute angle present with a para-oesophageal hernia, which is generally recognized as preventing regurgitation. When there is an acute angle of implantation the control of reflux is materially helped by the internal arrangements and in particular the flap of mucosa which is present over the acute angle (Dornhorst, Harrison, and Pierce, 1954). If the whole area is shaped like a thistle funnel the mucosa will be flattened out and no such flap valve will be present. From every aspect therefore it seems desirable that the angle of implantation should be made more acute, and to produce this the suturing must be done from above down.

It was previously maintained (Collis et al., 1954) that the crural muscle served two functions. The first of these was the maintenance of the angle of implantation in all stages of the respiratory cycle and the other was a sphincter action. The former is mainly produced by the longitudinal fibres and the latter by the oblique and transverse fibres. It is not considered that this last function is a very important or essential one, but the action of these fibres will be helped by reduction in the size of the hiatus. This function would be made more effective whether the hiatus was sutured from above or below the oesophagus.

One problem is created by insistence that the suturing be done from above. This is that it becomes more difficult in some cases to reduce the hernia because a greater length of oesophagus is required. This problem is more apparent than real because it does not seem to matter a great deal at what point the change from gastric to oesophageal mucosa occurs as long as reflux is controlled. Therefore, providing the tube passing through the diaphragm is a small one, and similar in size to a normal oesophagus, a good angle of implantation will be obtained and good control of reflux will be produced.

\section{Operative TechniQue}

This was fully described (Collis, Satchwell, and Abrams, 1954), but as certain minor modifications have been made it is thought best to restate the whole procedure.

The patient is placed on the table lying on his back with the left side raised by a sand-bag. The arms are placed to the sides. An incision is made obliquely from the umbilicus to the mid-axillary line along the seventh intercostal space. The space is chosen according to which one points to the umbilicus, and no attempt is made to count the ribs. The latissimus dorsi is raised and the fibres of the serratus anterior separated to bring the dissection down to the chest wall. This is carried forwards across the interdigitation of the external oblique muscle and down to the rectus sheath. The rectus is completely divided. The chest is opened in the seventh intercostal space and a segment of costal cartilage removed. The peritoneum is opened where it presents between the interdigitations of the diaphragm and the transversus abdominis, and this opening is carried forward through the posterior rectus sheath. The incision of the diaphragm is considered of special importance, and this is the subject of a modification in the previous method. The incision is now made so as to do the minimum of damage to the branches of the phrenic nerve. This nerve has three main divisions: the anterior, which is not in danger; the lateral, which may be a single branch but is often a series of loops; and the posterior division. These last two divisions are in danger. The incision must keep close to the costal margin until it can be brought centrally between them. Further, it must not be carried further centrally than half an inch short of the central tendon so as not only to avoid the posterior branch but also to prevent overstretching it. This results in the incision in the diaphragm having an angulated shape. It starts close to the costal margin and continues here for about $5 \mathrm{~cm}$. before turning centrally. The vessels accompanying the lateral branch of the right phrenic nerve can be seen on the upper surface of the diaphragm, so that there is no real difficulty in avoiding them. This care with the nerve supply causes an increased difficulty in making the incision, but it results in a normally functioning diaphragm after operation.

The diaphragm is now retracted upwards. The area of the hiatus is then examined. At the same time the whole stomach and the duodenum are inspected to see if peptic ulceration or scarring is present. The gall bladder is also palpated and viewed. The dissection of the hiatus is done from its inferior aspect and is begun on the left side of the oesophagal opening, and the left half of the right crus is cleared. The gut is now retracted to the left and the lesser omentum is incised and the accessory hepatic vessels are divided between haemostats. This brings into view the caudate lobe of the liver and the inferior vena cava. It also reveals the right half of the right crus. The peritoneum is 
incised along the left margin of this as far away from the edge of the muscle as possible. The peritoneum will retract, and it is very desirable that it should not leave the surface of the right crus bare. If this happens, the muscle fibres tend to separate when the stitches are put in at a later stage. The dissection is now carried up over the upper surface of the gut and Allison's ligament is divided. Lastly, the lower margin of the gut is freed and a sling put around it. The gut can now be lifted up and the final clearing of both limbs of the right crus can be completed. This is done right down to its tendon of origin and the double-breasted overlap is opened up. This can be exaggerated a little with scissors, and in so doing a bed for the oesophagus to lie in is prepared.

The muscle of the right crus is assessed for strength and type, and the mobility of the gut is tested to check that the oesophagus is long enough to reach the hiatus. The first stitch is now put in. This is inserted between the top of the tendon of origin of the right crus and the back of the oesophagus in the region of the cardia. This step was not done originally, but it is now felt that it seals an important angle where recurrence may start. The oesophagus is now lying in its bed on top of the tendon of the right crus and held there by the one stitch mentioned. The stitch must only hold it down in this position and it must not close the two leaves of the crus together. If the latter is done it will limit the production of an acute angle of implantation between the oesophagus and the stomach.

The stitching of the two leaves of the right crus now begins above and in front of the oesophagus. On the left the stitches are placed as far round the edge of the crus as possible. This means that they are as much on the upper surface as possible. The edge of the left half of the right crus has to be turned round to obtain the place of insertion. Each stitch is put in carefully in this way because without this precaution they tend to drift farther and farther to the left. If this drifting occurs it produces tension and distortion. Done properly, the stitching results in the oesophagus passing obliquely through a tunnel in the diaphragm, which aids the chances of its being gripped by the muscular action of the right crus. Even with quite a small hiatus the stitches placed in this way result in a considerable lowering of the point around which the oesophagus angulates. This lowering amounts to at least $3 \mathrm{~cm}$. There would seem to be very little danger of making the hiatus too small in this way, as more stitches are really increasing the length of the tunnel rather than making it narrower. Although some patients have had some early postoperative dysphagia produced by this, no patient has had to have any radical treatment for it, and in no case has any permanent dysphagia been produced. Lastly the fundus of the stomach is attached to the dome of the diaphragm in two places and the chest and abdomen are closed without drainage. One thread pericostal is used near the costal margin. This is considered rather an admission of failure, but in two cases this area has given way requiring further surgery. This is the straightforward operation, but it can be combined with partial gastrectomy or even with cholecystectomy, although the view for the latter is not perfect.

There are a few special points about the immediate post-operative period. If the patient should have some dysphagia in the early days it need cause no alarm and may even be rather desirable. The patient can be assured that it will improve. In rare cases it has been very bad for a few days and has even required that parenteral fluid be given, but never any other measures. This statement only applies to the reducible hiatus herniae. When special measures are taken to deal with a short oesophagus the position is different and is not being considered here.

\section{Follow-UP}

General Material.- It was found that from the middle of 1953 when this operation was started until early in 1960 the procedure had been used for 200 patients. The operation has been used at all ages, but the largest numbers are in the older age groups (Table I). The large proportion of cases at an older age is considered to be a fair

TABLE I

AGE OF 200 PATIENTS

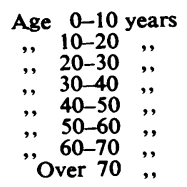

$$
\left.\begin{array}{r}
3 \\
0 \\
6 \\
19 \\
39 \\
76 \\
47 \\
10
\end{array}\right\} 162=86 \%
$$

picture of the situation although to some extent exaggerated by the practice from which the cases are drawn (see also Morris, 1956).

The sex incidence followed the pattern reported in the other follow-up series (Table II). Twothirds of the patients are women (Gertz, Regout,

TABLE II

SEX DISTRIBUTION OF 200 PATIENTS

\begin{tabular}{llll}
$\mathbf{M}$ &. &. & $76(38 \%)$ \\
$\mathbf{F}$ & $\cdots$ & $\ldots$ & $124(62 \%)$ \\
\hline
\end{tabular}

and Thomsen, 1951 ; Stensrud, 1954 ; Robb, 1954 ; Morris, 1956 ; Humphreys, Ferrer, and Wiedel, 1957).

It is difficult to give any figure for the proportion of patients with hiatus hernia who are being treated surgically. In...this series patients have only been selected for surgery after other methods have failed or are not likely to produce relief. This statement ultimately collects a high proportion to surgical treatment and certainly 
many more than the $5-10 \%$ suggested by Avery Jones in 1952. The feeling is in accord with Robb's (1954) view that when a definite hernia is present with symptoms the patient is not easily put off and forces one's hand. Naturally the patients are already the subject of selection before they reach the surgeon, but of the ones with a definite hernia reaching the surgical out-patient department over $75 \%$ have been treated surgically.

In this series the sliding type of hernia has been more common than the para-oesophageal, the figures being $86 \%$ sliding and $14 \%$ paraoesophageal. This is in general accord with all published series. In a proportion it has been found that the oesophagus is so short that the standard operation suggested cannot be used. In $10 \%$ other operative procedures have been used, but this figure is swollen by a number of patients in the older age groups with short oesophagus and stricture formation who have been treated conservatively.

In four patients achalasia and hiatus hernia have coexisted $(2 \%)$. This is an awkward combination, but has not prevented both a plastic repair and a Heller's operation giving good results. In five patients $(2.5 \%)$ peptic ulcer unassociated with the hiatus hernia has been of a severity to require partial gastrectomy to be done at the same time as the plastic repair. In a further five cases $(2.5 \%)$ the gall bladder had to be removed at the same operation.

In the whole series there have been four immediate post-operative deaths. One was a death on the table associated with the anaesthetic. One was due to a pulmonary embolism in a patient otherwise ready for discharge. The other two deaths were in patients with very large paraoesophageal herniae. One of these patients also had acromegaly. It is felt that this high death rate in large para-oesophageal hernia is a true picture of the likely risk.

LONG-TERM FOLLOW-UP.-Of particular importance are the findings from those patients who have been observed for more than four years. There were 82 of these and a $100 \%$ follow-up has been obtained (Table III). The survey has included both personal interview and barium swallow studies. As much attention has been paid to the degree of success in controlling reflux as to the removal of the actual hernia. The practice has been to carry out a barium swallow examination before each patient leaves hospital, at one year after operation, and at the four-year stage. At each of these examinations both surgeon and radiologist are present and determined efforts are
TABLE III

FOLLOW-UP OF 82 PATIENTS WITH HIATUS HERNIA, 1953-6

\begin{tabular}{|c|c|c|c|}
\hline & & At One Year & At Four Years \\
\hline $\begin{array}{l}\text { Symptoms: } \\
\begin{array}{l}\text { Good } \\
\text { Improved }\end{array} \\
\text { No better } \\
\text { Died } \quad . \\
\end{array}$ & $\begin{array}{l}. . \\
\because \\
\cdots \\
. .\end{array}$ & $\begin{array}{l}66(82 \%) \\
12 \\
3 \\
1\end{array}$ & $\begin{array}{l}64(80 \%) \\
13 \\
1 \\
4\end{array}$ \\
\hline $\begin{array}{l}\text { Reflux: } \\
\text { Nil or slight } \\
\text { Moderate } \\
\text { Free } \\
\text { Recurrence } \\
\text { Never reduced }\end{array}$ & $\begin{array}{l}\cdots \\
\cdots \\
\cdots \\
\cdots\end{array}$ & $\begin{array}{l}73(91 \%) \\
3 \\
5 \\
2 \\
7\end{array}$ & $\begin{array}{l}60(75 \%) \\
9 \\
9 \\
1 \\
5\end{array}$ \\
\hline
\end{tabular}

made in the test for reflux. These consist of lying the patient down and getting her to roll from the left side to the right, coughing as she goes. This sort of action, by catching the control mechanism off its guard, seems to be the most effective in producing reflux and much more likely to produce it than steady pressure. This, however, is also used, and the patients have this while they raise their legs from the table and also cough. If at any time in this testing a free flow of barium comes up into the oesophagus the result of the test is classed "free reflux." Johnstone (1955) allows a patient to have one reflux and still be classed as normal, but in this series the amount refluxed has had to be very small for this to be accepted.

In assessing the symptoms, attention has been confined to matters that could conceivably be associated with the hiatus hernia. Inevitably in a series in this age group other symptoms arise but have not been recorded. There have been two recurrences. In one it took the form of a paraoesophageal hernia where the previous one had been a sliding hernia, and in the other it was a sliding hernia recurring as a sliding hernia. One of these had a further operation and was satisfactory at four years. In seven patients a record was made at operation that the cardia could not be completely returned to its normal site, and this situation remained at both examinations without getting worse in five instances. The other two patients died before the four-year check. In one of these the patient was 78 at the time of operation and the cause of his death was not associated with the hiatus hernia. The other continued with troublesome oesophagitis and dysphagia, and although she died from pneumonia it was clearly related to the hiatus hernia. The remaining five were certainly not the only ones in whom the cardia could not be brought to the hiatus, but they were the ones where the discrepancy was most marked. Sometimes it is difficult to be certain of the exact position of the 
cardia. Where difficulty in deciding exists, it means that the tube at the hiatus is of the same size as a normal oesophagus and it is not thought to upset the results. This is strongly supported in the figures. Of the five marked as never reduced and followed up for four years, four had no reflux at one year and one had free reflux, but four had free reflux at four years. It will be seen that an undue proportion of the cases showing a worsening in their control of reflux after four years comes from this one source.

The comparison between the state by symptoms at one and four years is generally satisfactory. Two of the four deaths have just been mentioned and one was a death on the table also already recorded. The last death was from carcinoma of the breast in a patient symptom-free from the hiatus hernia. Of the section who were no better at one year, one died and one had a reoperation, so that this number of three was reduced to one at four years.

The comparison of the state of reflux at one year and four years is not quite so good as the maintenance of improvement by symptoms. In large measure the appearance of free reflux is associated with leaving the cardia above the hiatus as already mentioned. The main part of the other change was from " nil or slight" to "moderate," and it is this which is compatible with little change in symptomatic relief. One other problem occurred in that one patient had the development of a diaphragmatic hernia adjacent to the costal margin without any recurrence or reflux at the hiatus. This complication was repaired and the patient is satisfactory.

\section{CONCLUSIONS}

The operation for plastic repair of the oesophageal hiatus is well tolerated and effective in giving relief of symptoms.

When the oesophagus is materially short it is not satisfactory to use this operation.

The control of both the hernia and reflux is well maintained at four years.

My special thanks are due to my radiological colleagues who have been so generous with their assistance in following up these patients. Particular mention should be made of the help given by Dr. O. E. Smith, Dr. P. Jacobs, Dr. J. E. Glasgow, and Dr. J. D. H. Wearing.

\section{REFERENCES}

Allison, P. R. (1948). Thorax, 3, 20.

Barrett, N. R. (1952). Proc. roy. Soc. Med., 45, 279.

Collis, J. L., Kelly, T. D., and Wiley, A. M. (1954). Thorax, 9, 175. - Satchwell, L. M., and Abrams, L. D. (1954). Ibid., 9, 22.

Dornhorst, A. C., Harrison, K., and Pierce, J. W. (1954). Lancet, 1,695 .

Gertz, T. C., Regout, J. E. P. M., and Thomsen, G. (1951). Thorax, 6, 316.

Humphreys, G. H., Ferrer, J. M., and Wiedel, P. D. (1957). J. thorac. Surg., 34,749

Johnstone, A. S. (1955). Brit. J. Radiol., 28, 229.

Jones, F. Avery (1952). Proc. roy. Soc. Med., 45, 277.

Morris, K. N. (1956). Med. J. Aust., 2, 128.

Robb, D. (1954). Aust. N.Z. J. Surg., 24, 18.

Stensrud, N. (1954). Acta chir. scand., 107, 57.

Tanner, N. C. (1955). Lancet, 2, 1050. 